\title{
Changes in Appetitive Associative Strength Modulates Nucleus Accumbens, But Not Orbitofrontal Cortex Neuronal Ensemble Excitability
}

\author{
ㄱoseph J. Ziminski, Sabine Hessler, Gabriella Margetts-Smith, ${ }^{\circledR}$ Meike C. Sieburg, Hans S. Crombag, \\ and $\odot$ Eisuke Koya \\ Sussex Neuroscience, School of Psychology, University of Sussex, Falmer BN1 9QG, United Kingdom
}

Cues that predict the availability of food rewards influence motivational states and elicit food-seeking behaviors. If a cue no longer predicts food availability, then animals may adapt accordingly by inhibiting food-seeking responses. Sparsely activated sets of neurons, coined "neuronal ensembles," have been shown to encode the strength of reward-cue associations. Although alterations in intrinsic excitability have been shown to underlie many learning and memory processes, little is known about these properties specifically on cue-activated neuronal ensembles. We examined the activation patterns of cue-activated orbitofrontal cortex (OFC) and nucleus accumbens (NAc) shell ensembles using wild-type and Fos-GFP mice, which express green fluorescent protein (GFP) in activated neurons, after appetitive conditioning with sucrose and extinction learning. We also investigated the neuronal excitability of recently activated, GFP + neurons in these brain areas using whole-cell electrophysiology in brain slices. Exposure to a sucrose cue elicited activation of neurons in both the NAc shell and OFC. In the NAc shell, but not the OFC, these activated GFP + neurons were more excitable than surrounding GFP - neurons. After extinction, the number of neurons activated in both areas was reduced and activated ensembles in neither area exhibited altered excitability. These data suggest that learning-induced alterations in the intrinsic excitability of neuronal ensembles is regulated dynamically across different brain areas. Furthermore, we show that changes in associative strength modulate the excitability profile of activated ensembles in the NAc shell.

Key words: appetitive learning; Fos; intrinsic excitability; neuronal ensemble; nucleus accumbens; prefrontal cortex

Significance Statement

Sparsely distributed sets of neurons called "neuronal ensembles" encode learned associations about food and cues predictive of its availability. Widespread changes in neuronal excitability have been observed in limbic brain areas after associative learning, but little is known about the excitability changes that occur specifically on neuronal ensembles that encode appetitive associations. Here, we reveal that sucrose cue exposure recruited a more excitable ensemble in the nucleus accumbens, but not orbitofrontal cortex, compared with their surrounding neurons. This excitability difference was not observed when the cue's salience was diminished after extinction learning. These novel data provide evidence that the intrinsic excitability of appetitive memoryencoding ensembles is regulated differentially across brain areas and adapts dynamically to changes in associative strength.

\section{Introduction}

Animals use cues that predict the availability of food rewards to guide their behavior and maximize food-seeking strategies (Petrovich,

Received Dec. 8, 2016; revised Jan. 19, 2017; accepted Jan. 29, 2017.

Author contributions: J.J.Z., H.S.C., and E.K. designed research; J.J.Z., S.H., G.M.-S., and M.C.S. performed research; J.J.Z., S.H., G.M.-S., M.C.S., H.S.C., and E.K. analyzed data; J.J.Z., S.H., G.M.-S., M.C.S., H.S.C., and E.K. wrote the paper.

This work was supported by the Biotechnology and Biological Sciences Research Council (BBSRC Grant BB/ M009017/1), University of Sussex Strategic Development Funds, Sussex Neuroscience (4-year doctoral program), and Sussex School of Psychology Impact Funds. We thank Drs. Carl Lupica and Alex Hoffman at NIDA IRP (Baltimore) for many fruitful discussions and advice on conducting electrophysiology experiments; Alex Hoffman for critically reading this manuscript; Stephanie Fisher for excellent technical support in managing the transgenic mouse colony: Leonie Brebner for technical assistance with the behavioral experiments and image analysis using Fiji; and Dave Mawer for technical assistance with the behavioral experiments.
2011). In humans and nonhuman animals, stimuli that are associated with palatable foods powerfully shape behavior and increase motivation to consume food (Petrovich and Gallagher, 2007; Anschutz et al., 2011; van Strien et al., 2012). Conversely, animals rapidly inhibit such learned appetitive responses when previously food-associated cues no longer predict food availability (Pavlov, 1927; Mackintosh, 1983). Identifying how these learned associations are encoded neuronally is crucial to illumi-

The authors declare no competing financial interests.

Correspondence should be addressed to Dr. Eisuke Koya, Sussex Neuroscience, School of Psychology, University of Sussex, Falmer BN1 90G, United Kingdom. E-mail: e.koya@sussex.ac.uk.

DOI:10.1523/JNEUROSCI.3766-16.2017

Copyright $\odot 2017$ the authors $\quad 0270-6474 / 17 / 373160-11 \$ 15.00 / 0$ 
nating the mechanisms underlying disorders characterized by excessive food intake, such as obesity.

Exposure to food-associated cues activates brain areas that subserve motivational processes, such as the nucleus accumbens (NAc) and prefrontal cortex, which also play a pivotal role in encoding food-predictive cues and changes in cue-reinforcer contingencies (Annett et al., 1989; Schoenbaum et al., 2003; Day et al., 2006; Schoenbaum et al., 2007; Singh et al., 2010; Flagel et al., 2011; Petrovich, 2011; Burger and Berner, 2014; Warren et al., 2016). Moreover, there is now evidence indicating that, within both of these regions, associative memories may be encoded in sparsely activated subsets of neurons called neuronal ensembles (Pennartz et al., 1994; Koya et al., 2009; Fanous et al., 2012; Cruz et al., 2013; Warren et al., 2016; Whitaker et al., 2016). These ensembles exhibit synaptic adaptations that are not observed in surrounding nonactivated neurons after learning (Koya et al., 2012; Gouty-Colomer et al., 2016; Whitaker et al., 2016). Therefore, appetitive associations may be encoded through adaptations occurring in multiple neuronal ensembles existing in multiple brain areas.

During experience-dependent plasticity, neurons may fine-tune information transfer by modifying their connectivity to surrounding neurons at the synapse, but also by adapting their intrinsic excitability (Dong et al., 2006; Kourrich et al., 2015). Alterations in neuronal excitability modulate neuronal firing properties and thus the ability of neurons to influence the activity of local and distal postsynaptic neurons (Nisenbaum and Wilson, 1995; Daoudal and Debanne, 2003; Santini et al., 2008). These excitability changes have been widely observed after aversive conditioning in brain areas that encode emotionally salient stimuli, such as the amygdala and prefrontal cortex (Quirk and Mueller, 2008; Santini et al., 2008; Sehgal et al., 2014). However, in these studies, neuronal excitability was measured from a randomly sampled neuronal population within a given brain area without taking neuronal activation history into account. Therefore, little is known about changes in the intrinsic excitability of neurons that occur in behaviorally relevant ensembles activated by appetitive cues.

The aim of this study was to characterize intrinsic excitability changes of cue-activated neuronal ensembles in the shell portion of the NAc and orbitofrontal cortex (OFC) after appetitive conditioning with sucrose reward and extinction learning using FosGFP mice, which express green fluorescent protein (GFP) in strongly activated neurons (Barth et al., 2004; Koya et al., 2012; Whitaker et al., 2016). Both the NAc shell and OFC are activated by food-associated cues and are implicated in appetitive behaviors that are guided by learned associations and updating changes in learned contingencies (e.g., extinction; Schoenbaum et al., 2003; Day et al., 2006; Schoenbaum et al., 2007; Singh et al., 2010; Fanous et al., 2012; Moorman and Aston-Jones, 2014). We hypothesized that changes in associative strength may modulate the excitability properties of the cue-activated neuronal ensembles in these areas.

\section{Materials and Methods \\ Animals}

Male Fos-GFP mice (https://www.jax.org/strain/014135; RRID:IMSR_ JAX:014135) previously bred onto a C57BL/6 background were bred with wild-type C57BL/6 females obtained from Charles River Laboratories at the University of Sussex. Heterozygous Fos-GFP male mice continued to be bred at the University of Sussex ancillary unit with wild-type C57BL/ 6 females obtained from Charles River Laboratories UK. Fos-GFP male mice were used for electrophysiology and immunofluorescence experiments and C57BL/6 wild-type males were used for in situ hybridization studies. All mice were housed under a $12 \mathrm{~h}$ light/dark cycle (lights on at 7:00 A.M.) at the maintained temperature of $21 \pm 1{ }^{\circ} \mathrm{C}$ and $50 \pm 5 \%$ relative humidity. Animals were aged 10-12 weeks at the beginning of behavioral testing and were food restricted ( $90 \%$ baseline body weight) 1 week before behavioral testing until the completion of the behavioral experiments. All experiments were conducted in accordance with the UK 1986 Animal Scientific Procedures Act and received approval from the University of Sussex Ethics Committee.

\section{Behavioral experiments \\ Apparatus}

All behavioral experiments were performed in standard mouse operant chambers $(15.9 \times 14 \times 12.7 \mathrm{~cm}$; Med Associates), each housed within a sound-attenuating and light-resistant cubicle. The conditioning chamber front and rear access panels and ceiling were constructed from clear Plexiglas and the side walls were made from removable aluminum panels atop a stainless steel grid floor. Each chamber was fitted with a recessed magazine situated in the center of one side wall that dispensed a $10 \%$ sucrose solution serving as the unconditioned stimulus (US). An infrared beam detected head entries into the food magazine. The house light was situated in the side panel and was on for the duration of the behavioral experiments. A mechanical click generator provided a broad-frequency $(0-15 \mathrm{kHz})$ sound, which served as a conditioned stimulus (CS) (Med Associates). Initiation and running of behavioral protocols, including the recording of head entries into the food magazine, was performed using Med-PC IV (Med Associates).

\section{Procedures}

Magazine training and Pavlovian conditioning. Mice were randomly assigned to the Paired or Unpaired groups that underwent identical procedures except that Unpaired mice only received sucrose in the home cage 1-4 $\mathrm{h}$ at random times before or after each conditioning (acquisition) session. One day after magazine training, in which Paired mice were pretrained to the sucrose-delivery magazine, where they received a $10 \%$ sucrose solution under a random interval-30 (RI-30) schedule, mice underwent 12 acquisition sessions over a $7 \mathrm{~d}$ period in the morning (8:00 A.M. to 12:00 P.M.) and/or afternoon (12:00 P.M. to 5:00 P.M.) for 1-2 sessions per day. Each acquisition session lasted approximately $24 \mathrm{~min}$ and consisted of six $120 \mathrm{~s}$ CS presentations separated by $120 \mathrm{~s}$ RI intertrial interval (ITI) periods. During each $120 \mathrm{~s}$ CS period, $13.3 \mu \mathrm{l}$ of $10 \%$ sucrose solution was delivered into the magazine on an RI-30 s schedule (Paired mice) or was unrewarded (Unpaired mice). Twelve acquisition sessions produced selective responding to the CS (see Fig. 2A).

Behavioral testing for Pavlovian approach conditioning (Histology and Electrophysiology Experiments 1). At 7-9 d (histology experiment) and 7-13 d (electrophysiology experiment) after the last acquisition session, both Paired and Unpaired mice were placed in the conditioning chamber and tested under extinction conditions (see Fig. 1A).

Behavioral testing for extinction learning experiments (Histology and Electrophysiology Experiments 2). After magazine training and acquisition, mice in the extinction (EXT) experiments (Paired EXT and Unpaired EXT) underwent either 8 (histology) or 7-13 (electrophysiology) once-daily extinction sessions until test day (the final extinction session). During each extinction session, only the CS was presented in the absence of sucrose delivery. In the histology experiments, a third group (Paired No EXT) was included and the experiment was conducted identically to the Paired mice in the previous Pavlovian approach experiments (see Fig. 1B).

Spontaneous recovery (SR) of Pavlovian approach. An additional group of Paired wild-type mice underwent conditioning and extinction sessions similar to the Paired EXT mice described above. After the last extinction session (EXT final), they remained in the colony room for an additional 6-7 $\mathrm{d}$ and were subsequently tested for SR of Pavlovian approach responding (see Fig. 5B).

\section{Histology experiments}

\section{GFP immunofluorescence histochemistry}

Ninety minutes after initiating the final test session, Fos-GFP mice were anesthetized with $200 \mathrm{mg} / \mathrm{kg}$ sodium pentobarbital and transcardially perfused with $4 \%$ paraformaldehyde. GFP immunofluorescence was 
Table 1. Basic membrane properties from the NAc shell (MSNs) and OFC (pyramidal neurons) after Pavlovian approach test

\begin{tabular}{|c|c|c|c|c|c|c|c|c|}
\hline & \multicolumn{4}{|l|}{ NAc shell } & \multicolumn{4}{|l|}{ OFC } \\
\hline & \multicolumn{2}{|l|}{ Unpaired } & \multicolumn{2}{|l|}{ Paired } & \multicolumn{2}{|l|}{ Unpaired } & \multicolumn{2}{|l|}{ Paired } \\
\hline & GFP- & GFP+ & GFP- & GFP+ & GFP- & GFP+ & GFP- & $\mathrm{GFP}+$ \\
\hline Rheobase (pA) & $52.43 \pm 4.39$ & $52.00 \pm 4.76$ & $51.79 \pm 3.41$ & $39.38 \pm 3.24$ & $108.54 \pm 16.81$ & $120.71 \pm 13.75$ & $107.08 \pm 23.72$ & $106.46 \pm 13.75$ \\
\hline$R_{\mathrm{i}}(\mathrm{m} \Omega)$ & $387.60 \pm 24.17$ & $385.52 \pm 46.69$ & $351.23 \pm 14.77$ & $498.15 \pm 39.64^{* * *}, \#$ & $158.36 \pm 15.63$ & $162.74 \pm 15.29$ & $227.21 \pm 26.90 \dagger$ & $186.79 \pm 18.19+$ \\
\hline AP peak (mV) & $60.8 \pm 2.36$ & $61.62 \pm 4.37$ & $71.05 \pm 2.00$ & $67.40 \pm 3.24$ & $82.19 \pm 2.01$ & $77.34 \pm 2.43$ & $78.53 \pm 2.28$ & $79.50 \pm 1.73$ \\
\hline $\mathrm{mAHP}(\mathrm{mV})$ & $-8.08 \pm 0.44$ & $-8.20 \pm 0.52$ & $-9.64 \pm 0.47$ & $-8.57 \pm 0.67$ & $-8.10 \pm 0.87$ & $-8.79 \pm 0.82$ & $-7.20 \pm 1.19$ & $-8.31 \pm 1.23$ \\
\hline
\end{tabular}

Data are expressed as mean \pm SEM $\left(* * * p<0.001,+p<0.05\right.$, \#p <0.05). \#Significant interaction of Condition $\times$ GFP; ${ }^{* * *}$ significant differences between Paired GFP + compared with Paired GFP $-; \nmid$ tmain effect of Condition. Liquid junction potential was $-11.1 \mathrm{mV}$ and was not adjusted for. Spike characteristics were determined from the first action potential (AP) of spike runs consisting of $6-8$ spikes. Input resistance was calculated from slope of the I/V curve measured in response to $2 \mathrm{pA}$ (NAc shell) or $5 \mathrm{pA}$ (OFC) current steps. The AP threshold was calculated by the third-order derivative method (Cotel et al., 2013) using Mini Analysis software. (In this method, the maximum value of the third derivative of the AP trace (d3Vm/dt3) was utilized to determine onset time of the AP and then the critical membrane voltage that was required to elicit an AP (AP threshold) was determined.) The AP peak was calculated as the difference between the AP peak and the AP threshold. Half-width was measured as the AP width at half-maximal spike. Postspike fAHPs and mAHPs were measured 3 and 30 ms after the AP threshold, respectively, similar to Ishikawa et al. (2009). $V_{\mathrm{m}}$, Resting membrane potential; $R_{\mathrm{i}}$, input resistance; fAHP, fast AHP; mAHP, medium AHP.

performed as described previously (Koya et al., 2012) and, unless specified otherwise, all steps were performed at room temperature. To assess GFP expression, free-floating sections were washed in Tris-buffered saline (TBS; $0.025 \mathrm{~m}$ Tris- $\mathrm{HCl}, 0.5 \mathrm{M} \mathrm{NaCl}, \mathrm{pH}$ 7.5) and blocked in $10 \%$ normal goat serum (catalog \#S-1000, RRID:AB_2336615; Vector Laboratories) in TBST (TBS, $0.2 \%$ Triton X-100). Slices were then incubated at $4^{\circ} \mathrm{C}$ overnight in anti-GFP primary antibody (catalog \#ab13970, RRID:AB_300798; Abcam) diluted 1/16000 in $3 \%$ normal goat serum TBST. The following day, slices were incubated for $2 \mathrm{~h}$ in antichicken 568 (catalog \#SAB4600039, RRID: AB_2631230; Sigma-Aldrich) at $1 / 200$ in TBST. Slices were mounted on Superfrost Plus slides (catalog \#UY-48512-00; Cole Parmer) air-dried, and coverslipped with PermaFluor (catalog \#TA-030-FM, RRID: SCR_014787; Thermo Scientific). Fluorescence images of GFP staining from left and right hemispheres of the NAc shell and OFC of 1-2 coronal sections per animal, corresponding to approximately bregma 1.18 and 2.46 (Paxinos and Franklin, 2001), respectively, were captured using a QI click camera (Qimaging) attached to an Olympus Bx53 microscope. GFP + nuclei were quantified using iVision software (version 4.0.15, RRID: SCR_014786; Biovision Technologies). The shell portion of the NAc was selected for this study because pilot experiments revealed sucrose-cue-induced GFP in this area.

In situ hybridization

Forty-five minutes after the final test session, mice were killed and their brains were removed and rapidly frozen in isopentane at $-50^{\circ} \mathrm{C}$. Then, $10 \mu \mathrm{m}$ sections containing the NAc shell (bregma 1.18) and OFC (bregma 2.46) were prepared using a Leica CM1900 cryostat. RNAscope in situ hybridization was performed as described previously (Rubio et al., 2015). All target probes were designed by Advanced Cell Diagnostics and targeted the mRNA of Fos (GenBank accession number NM_010234.2: target region, 443-1447), Slc17a7 (glutamate transporter; GenBank accession number NM 182993.2: target region, 464-1415), Slc32al (GABA transporter; GenBank accession num-
A

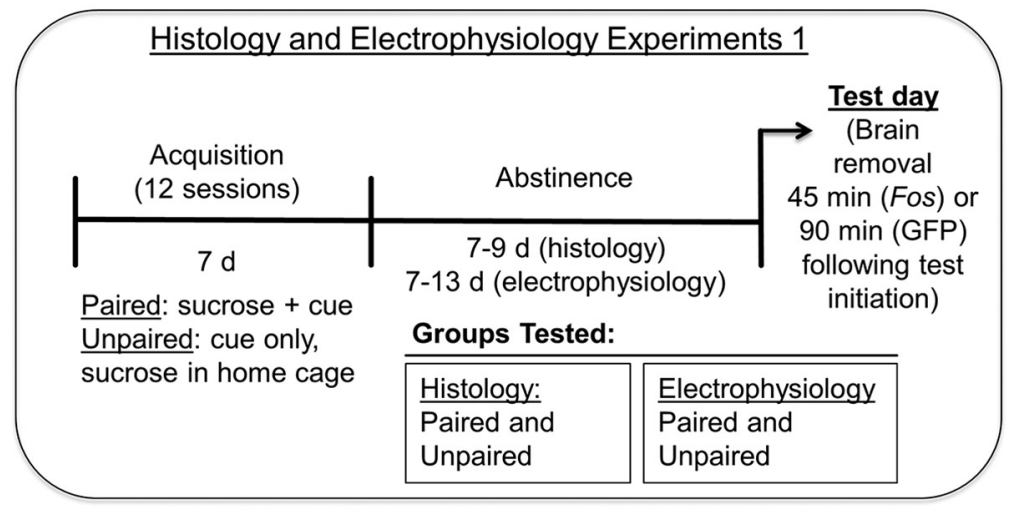

B

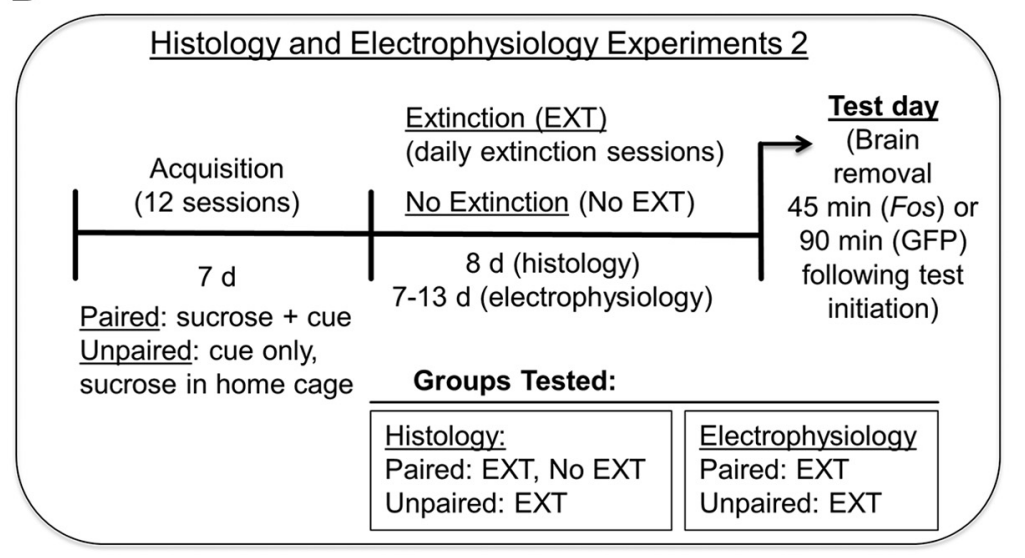

Figure 1. Timeline for Pavlovian approach and extinction experiments. $\boldsymbol{A}$, In Pavlovian approach experiments, two groups of mice underwent 12 acquisition (Pavlovian conditioning) sessions. In each session, Paired mice received sucrose during CS presentations in the conditioning chamber, whereas Unpaired mice received only $C S$ presentations and instead were given sucrose in their home cage at random times before or after each session. At 7-9 $d$ (histology experiments) or 7-13 d (electrophysiology experiments) after the last acquisition session, on test day, all mice were tested under extinction conditions and their brains were removed at 45 (Fos analysis) or 90 min (GFP immunohistochemistry and electrophysiology) after initiating testing. $\boldsymbol{B}$, In Extinction experiments, Paired and Unpaired mice underwent similar acquisition sessions as during Pavlovian approach experiments. One day after the last acquisition session a group of Paired and a group of Unpaired mice (EXT) underwent an extinction phase in which only the cue was presented. Another group of Paired mice did not undergo extinction learning (№ EXT). One extinction session was conducted per day and this phase lasted $8 \mathrm{~d}$ (histology experiments) or 7-13 $\mathrm{d}$ (electrophysiology experiments). Mice were killed on the final extinction session and their brains were removed at $45 \mathrm{~min}$ (Fos analysis) or $90 \mathrm{~min}$ (electrophysiology) after initiating testing. 


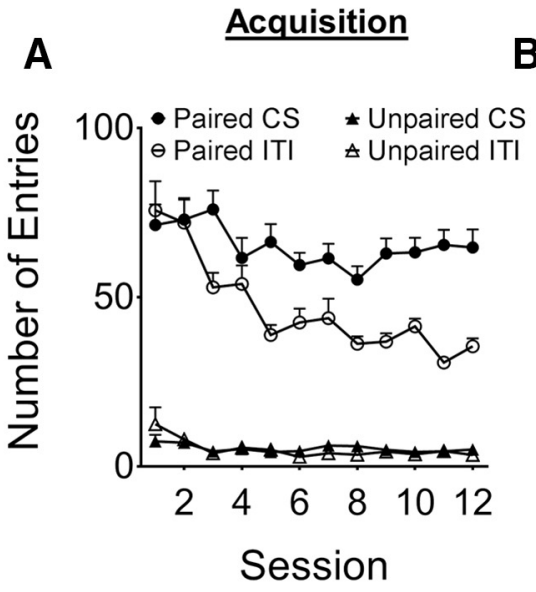

B Pavlovian approach

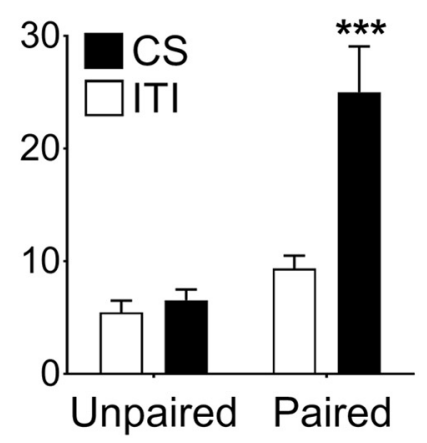

\section{GFP expression C following PA test}

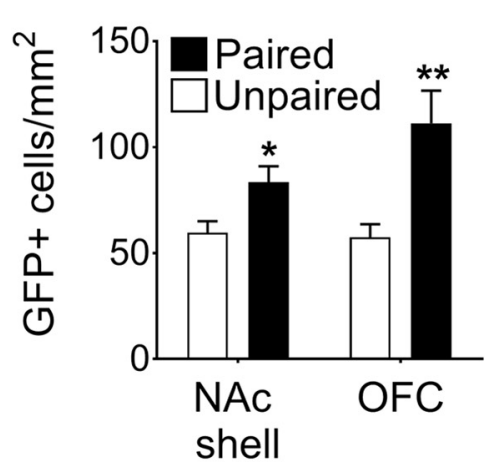

D
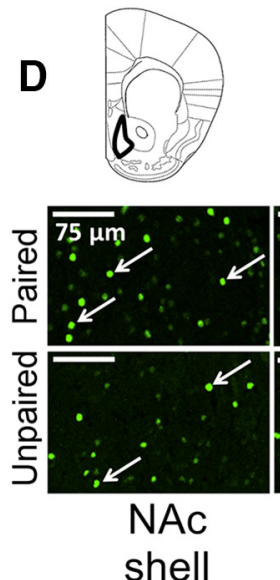
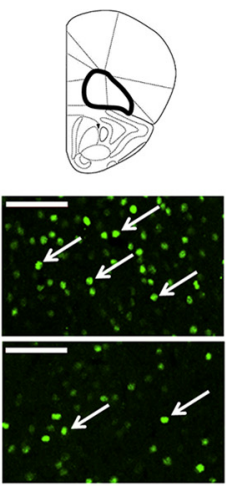

OFC

Figure 2. Sucrose cues evoke Pavlovian approach responses and enhance GFP expression in the NAc shell and OFC. $\boldsymbol{A}$, Head entries into the magazine in Unpaired and Paired mice during the CS and ITI periods ( $n=20 /$ group) during acquisition. $\boldsymbol{B}$, Head entries at test; CS head entries are significantly higher than ITI entries in the Paired, but not Unpaired group $\left({ }^{* * *} p<0.001\right)$. Asterisk indicates Paired CS compared with Paired ITI. C, GFP expression in the NAc shell and OFC; GFP expression is significantly higher in the Paired group compared with the Unpaired group for both brain areas $\left({ }^{* *} p<0.01,{ }^{*} p<0.05\right.$; NAc shell $n=$ 16-17/group, OFC $n=16 /$ group). D, Representative images of GFP immunohistochemistry in the NAc shell and OFC in Unpaired and Paired mice; white arrows indicate GFP + neurons. Data are expressed as mean \pm SEM.

ber NM_009508.2: target region, 894-2037), Drd1a (dopamine receptor 1; GenBank accession number NM_010076.3: target region, 4441358), and Drd2 (dopamine receptor 2; GenBank accession number NM_010077.2: target region, 69-1175). Probes were incubated with sections for $2 \mathrm{~h}$ at $40^{\circ} \mathrm{C}$. Fos, Drd1 a, and Drd2 mRNA were used as a marker for activated D1R- or D2R-expressing cells in the NAc shell, which form the direct and indirect pathways, respectively, that target overlapping but also distinct basal ganglia structures (Smith et al., 2013). OFCcontaining sections were hybridized with probes against Fos, Slc17a7a (vesicular glutamate transporter; VGLUT1) and Slc32a1 (vesicular GABA transporter; VGAT) to visualize Fos + pyramidal neurons or GABAergic interneurons, respectively. Sections were then incubated with three-step preamplifier and amplifier probes before being incubated with fluorescently labeled probes (Alexa Fluor 488, Atto 568, and Atto 647). Finally, a DAPI solution was briefly applied (for visualization of nuclei) and the slides were coverslipped with Vectashield Hard Set Antifade mounting medium (catalog \#H-1400, RRID:AB_2336787; Vector Laboratories).

Images of the NAc shell and OFC were taken using a Leica TCS SP8 confocal system attached to a DMI 6000 AFC Inverted Motorized Research Microscope at $20 \times$ magnification (HC PL APO $20 \times / 0.70$ CS), zoom factor 0.75 . The images were collected using Leica Application Suite X Confocal Software and analyzed in Fiji (RRID:SCR_002285).

\section{Electrophysiology experiments}

Separate cohorts of mice were run for NAc shell and OFC recordings (Experiment 1: $n=$ 20/12 Paired/Unpaired and Experiment 2: $n=16 / 18$, Paired/Unpaired).

Brain slice preparation and recording

Ninety minutes after the final behavioral test, mice were anesthetized with ketamine $(100 \mathrm{mg} /$ $\mathrm{kg}) /$ xylazine $(16 \mathrm{mg} / \mathrm{kg})$ and brains were removed and placed in ice-cold cutting aCSF containing the following (in $\mathrm{mM}$ ): 75 sucrose, 87 $\mathrm{NaCl}, 2.5 \mathrm{KCl}, 0.5 \mathrm{CaCl}_{2}, 7.0 \mathrm{MgCl}_{2}, 1.25$ $\mathrm{NaH}_{2} \mathrm{PO}_{4}, 25 \mathrm{NaHCO}_{3}$, and 10 D-glucose (bubbled with $95 \% \mathrm{O}_{2} / 5 \% \mathrm{CO}_{2}, \mathrm{pH} 7.4$ ) for $\sim 2 \mathrm{~min}$. Then, $250-\mu \mathrm{m}$-thick coronal slices that corresponded to approximately bregma $1.18-1.10$ for the NAc shell and 3.08-2.68 for the OFC were sectioned on a Leica VT1200S vibratome. After slicing, sections were briefly held in cutting aCSF for $5 \mathrm{~min}$ at $32^{\circ} \mathrm{C}$ before resting in recovery aCSF containing the following (in $\mathrm{mM}$ ): $125 \mathrm{NaCl}, 3$ $\mathrm{KCl}, 0.5 \mathrm{CaCl}_{2}, 3.5 \mathrm{MgCl}_{2}, 1.25 \mathrm{NaH}_{2} \mathrm{PO}_{4}, 25$ $\mathrm{NaHCO}_{3}$, and 10 D-glucose (bubbled with $95 \%$ $\mathrm{O}_{2} / 5 \% \mathrm{CO}_{2}, \mathrm{pH} 7.4$ ) at room temperature.

Single slices were hemisectioned along the midline and transferred to a recording chamber perfused with $30-32^{\circ} \mathrm{C}$ recording aCSF containing the following (in $\mathrm{mM}$ ): $2 \mathrm{CaCl}_{2}$ and $2 \mathrm{MgCl}_{2}$. Differential interference contrast (DIC) imaging was undertaken using an Olympus BX51WI microscope and the fluorescent signal was captured using an attached Revolution XD spinning disk confocal system (Andor Technology). GFP+ neurons were identified using a $488 \mathrm{~nm}$ laser line; cells that did not express GFP were considered to be GFP-. Whole-cell recordings from NAc shell medium-sized spiny neurons (MSNs) or OFC pyramidal neurons were performed using borosilicate capillary glass-pipettes $(1.5 \mathrm{~mm}$ outer diameter, $0.86 \mathrm{~mm}$ inner diameter) filled with the following (in mM): $135 \mathrm{~K}$-gluconate, $3 \mathrm{MgCl}_{2}, 4$ $\mathrm{NaCl}, 5$ HEPES, 5 EGTA, $2 \mathrm{Mg}$-ATP, $0.3 \mathrm{Na}_{3}$ GTP, pH 7.25, and $100 \mu \mathrm{m}$ Alexa Fluor 568 dye (A10437; Thermo Fisher Scientific). Patched cells were confirmed to be GFP + by colocalization of GFP and Alexa Fluor 568 observed before recording. Pyramidal neurons were identified based on their morphology under DIC microscopy (e.g., a prominent apical dendrite) and by their distinct firing patterns in response to current injections in current-clamp mode [e.g., action potential (AP) frequency accommodation; Cifani et al., 2012]. MSNs were identified based on their morphology, resting membrane potential, AP waveform and response to a $100 \mathrm{pA}$ hyperpolarizing current injection (Ishikawa et al., 2009).

The liquid junction potential was $-11.1 \mathrm{mV}$ and was not corrected. The current-clamp protocol consisted of $1 \mathrm{~s}$ positive current injections beginning at $-30 \mathrm{pA}$ and incrementing in $2 \mathrm{pA}$ (NAc shell) or $5 \mathrm{pA}$ (OFC) steps. MSNs were held at $-75 \mathrm{mV}$ and pyramidal neurons were held at $-70 \mathrm{mV}$ for the duration of recordings. Data were collected with a Multiclamp 200B amplifier (Molecular Devices) combined with Digidata BNC-20190 A (Molecular Devices) and WinWCP Software (courtesy of Dr. John Dempster, University of Strathclyde, Glasgow, UK; http://spider.science.strath.ac.uk/sipbs/software_ses.htm, RRID: SCR_014713). Signals were digitized at $10 \mathrm{kHz}$ and filtered at $5 \mathrm{kHz}$ (PCI 6024E; National Instruments) and $50 \mathrm{kHz}$ noise was filtered out using a HumBug (Quest Scientific) module. Spike kinetics were calculated using Mini Analysis Software (version 6.0; Synaptosoft) or manually [fast afterhyperpolarization (fAHP) and medium afterhyperpolarization (mAHP)] as described in Table 1. 
The current-clamp protocol consisted of $1 \mathrm{~s}$ positive current injections beginning at -30 $\mathrm{pA}$ and incrementing in $2 \mathrm{pA}$ and $5 \mathrm{pA}$ steps for MSNs and pyramidal neurons, respectively. MSNs were held at $-75 \mathrm{mV}$ and pyramidal neurons were held at $-70 \mathrm{mV}$ for the duration of recordings. More detailed information about the measured passive and active membrane properties are described in the legend of Table 1.

\section{Data analysis}

For the histology experiments, the group sizes for the GFP and Fos analyses are slightly less than that for behavioral analyses because a small number of sections could not be analyzed due to issues with transcardial perfusions and cryostat malfunctioning. In addition, for these experiments, cell counts that exhibited frequencies that were 2 SDs from the mean were excluded from analysis. Data from behavioral, histological, and electrophysiological experiments were analyzed using Prism software (RRID:SCR_002798; GraphPad Software) and SPSS software (RRID:SCR_002865; IBM). Group data are presented as mean \pm SEM.

\section{Behavior}

Total head entries into the sucrose-delivery magazine during CS and ITI presentation during acquisition and extinction were analyzed using a three-way mixed ANOVA including the factors of Condition (Paired, Unpaired), CS Presentation (CS, ITI) and a repeated-measures factor of session (1-12 for acquisition, 1-7 for extinction). Pavlovian approach test data were analyzed using a two-way ANOVA using CS Presentation (CS, ITI) and Training Condition (Paired, Unpaired). Spontaneous recovery test data were analyzed using a two-way ANOVA using CS Presentation (CS, ITI) and Test (EXT Final, SR Test) as factors. Pavlovian approach test data following extinction learning were analyzed using a two-way ANOVA using CS Presentation (CS, ITI), and Group (Paired No EXT, Unpaired EXT, Paired EXT) as factors.

\section{GFP and Fos mRNA expression}

In Experiments 1 and 2, $t$ tests on the number GFP+/Fos + neurons per square millimeter were conducted independently in the NAc shell and OFC using Condition (Paired, Unpaired) as a factor. In Experiment 3, a one-way ANOVA between Groups (Paired No EXT, Paired EXT, Unpaired EXT) was conducted on the number of Fos + neurons per square millimeter.

\section{Electrophysiology}

Resting membrane potential, input resistance, rheobase, and spike kinetics data were analyzed using two-way ANOVAs for Experiments 1 and 2 using Condition (Paired, Unpaired) and GFP (GFP+, GFP-) as factors. Spike counts for Experiments 1 and 2 were analyzed using a three-way mixed ANOVA including the factors of Condition (Paired, Unpaired), GFP $(\mathrm{GFP}+, \mathrm{GFP}-)$, and a repeated measures factor of Current Injections.

\section{Results}

Experiment 1: Pavlovian approach and neuronal activation in the NAc shell and OFC

For mice to acquire the relationship between the sucrose reward and a cue that predicts its availability, we used an appetitive Pav-

\section{B Fos expression following PA test}
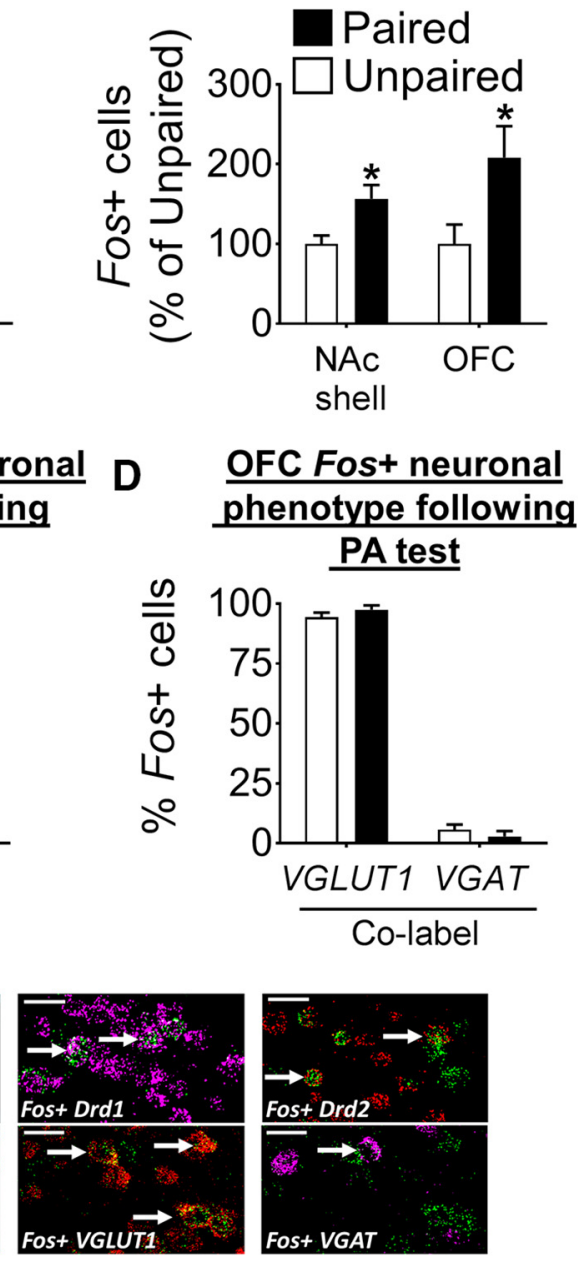

Figure 3. Characterization of activated neurons in the NAc shell and OFC after Pavlovian approach responding. $\boldsymbol{A}$, Head entries of mice used in in situ hybridization experiments at test ( $n=11-12 /$ group; $\left.{ }^{*} p<0.05\right)$. $\boldsymbol{B}$, Fos expression in the NAc shell and OFC after Pavlovian approach test expressed as percentage of Unpaired group; Fos expression is significantly higher in the Paired compared with the Unpaired group for both areas $\left({ }^{*} p<0.05 ; n=7-11 /\right.$ group). C, Proportion of Fos + neurons coexpressing (Fos + Drd1) or Drd2 (Fos + Drd2) in the NAc shell. D, Proportion of Fos + neurons coexpressing either VGLUT1 (Fos + interneurons. For $\boldsymbol{A}-\boldsymbol{D}$, data are expressed as mean \pm SEM. $\boldsymbol{E}$, Representative images of Fos, Drd1, and Drd2 labeling from the NAc shell (top row) and Fos, VGLUT1, and VGAT labeling from the OFC (bottom row). DAPI (blue) was used to visualize cell nuclei. White arrows indicate colabeled Fos + cells.

lovian conditioning procedure. To this end, we trained two groups of Fos-GFP mice, in which mice in the Paired group received auditory cue (CS) presentations paired with $10 \%$ sucrose solution (US) during each acquisition session (Fig. $1 A$ ) for a total of 12 sessions. In contrast, the Unpaired group received only cue presentations during each session and received similar amounts of sucrose in their home cages at random times before or after each session. Therefore, the CS in these mice remained neutral. As the training progressed, mice in the Paired group made significantly more CS entries compared with ITI entries (Fig. 2A). In contrast, CS and ITI entries remained low throughout the 12 acquisition sessions in mice in the Unpaired group. A three-way ANOVA revealed a significant effect of Condition $\times$ CS Presentation $\times$ Session interaction $\left(F_{(11,836)}=3.34, p<0.001\right)$, indicating that mice in the Paired group had reliably acquired the CS-US association. 


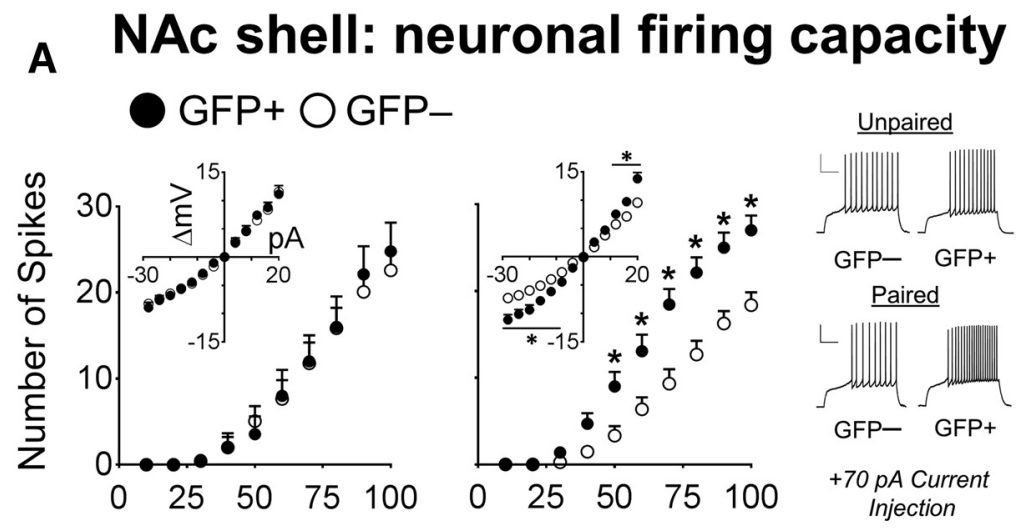

B OFC: neuronal firing capacity
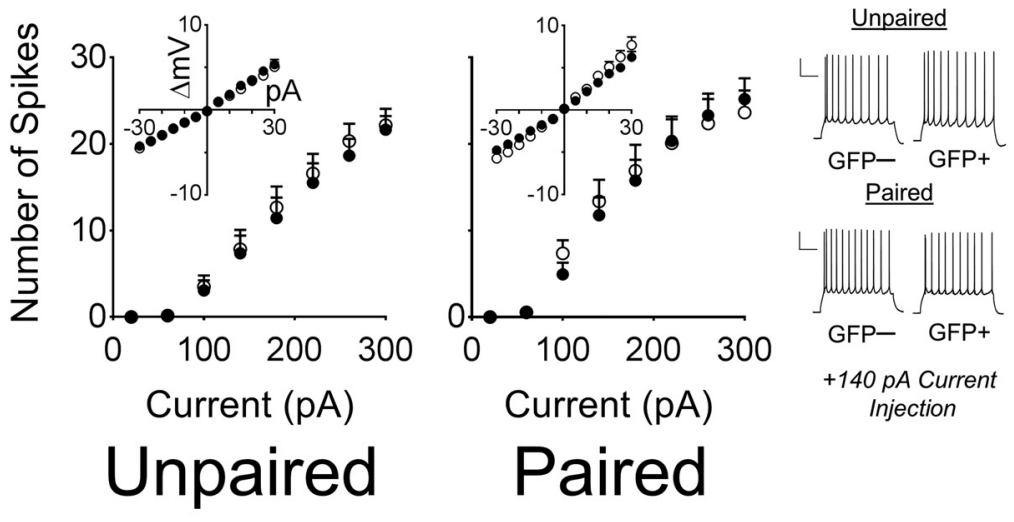

C

IV curve of OFC Paired vs. Unpaired GFP- neurons

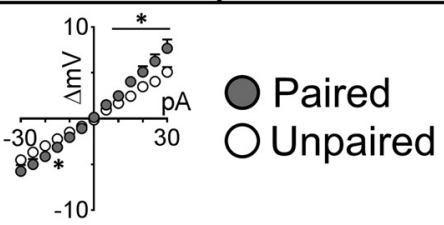

Figure 4. GFP + neurons activated by sucrose cues are more excitable compared with their surrounding GFP - neurons in the NAc shell but not the OFC. $A$, In the NAc shell, the spike counts of Paired group GFP + neurons were significantly increased compared with the GFP - neurons after current injections (GFP- $n=19 / 9 ; \mathrm{GFP}+, n=16 / 9){ }^{*} p<0.01$. In contrast, in the Unpaired groups, the spike counts of GFP + and GFP - neurons were similar (GFP - , $n=14 / 7 ; \mathrm{GFP}+, n=9 / 5$ ). The I/V curve (inset) indicated that there was a large increase in the input resistance of GFP + neurons in Paired mice, but no difference in the Unpaired mice. ${ }^{*} p<$ 0.05. Example traces of GFP + and GFP - neurons at $+70 \mathrm{pA}$ from the NAc shell of Paired and Unpaired mice. Scale bar, $25 \mathrm{mV}, 250$ ms. $\boldsymbol{B}$, In the OFC, no difference in spike counts was observed between GFP + and GFP - neurons in the Unpaired mice (GFP- , $n=12 / 5 ; \mathrm{GFP}+, n=14 / 5)$ and in Paired mice (GFP,$- n=11 / 5 ; \mathrm{GFP}+, n=17 / 5)$. The I/V curves of GFP + and GFP - neurons in Paired and Unpaired mice are shown in the inset. Example traces of GFP + and GFP - neurons in the OFC of Paired and Unpaired mice at $+140 \mathrm{pA}$ are shown. Scale bar, $25 \mathrm{mV}, 250 \mathrm{~ms}$. C, I/V curves of GFP - neurons from Paired and Unpaired mice from the OFC. ${ }^{*} p<0.05$. Data are expressed as mean $\pm \mathrm{SEM}$; values to the right of GFP - and GFP + denote number of cells recorded/number of mice used.

When Paired and Unpaired mice were tested 1 week after acquisition, Paired mice demonstrated a significant increase in number of head entries during presentation of the CS, a twoway ANOVA revealed a significant interaction of Condition $X$ CS presentation $\left(F_{(1,76)}=10.65, p<0.01\right.$; Fig. $\left.2 B\right)$. Post hoc analysis revealed significantly higher CS (cue presentation) compared with ITI (no cues) responses in the Paired group $(p<0.001)$, but not in the Unpaired group $(p=0.73)$.

Next, we examined neuronal activation in the NAc shell and the OFC in the same mice by counting GFP + neurons in these brain areas. The number of GFP + neurons in the Paired mice was significantly higher compared with Unpaired mice in both the
NAc shell $\left(144 \%\right.$ increase; $t_{(31)}=2.75$, $p<0.05)$ and the OFC (193\% increase; $t_{(30)}=3.23, p<0.01$; Fig. $\left.2 C\right)$. Therefore, mice in the Paired, but not the Unpaired, group exhibited Pavlovian approach responses and significant activation of NAc shell and OFC neurons, suggesting that these areas are activated by sucrose memories.

Phenotype of Fos-expressing neurons in the NAc shell and OFC

We next examined the phenotype of activated neurons in the NAc shell and OFC using RNAscope-based in situ hybridization. Consistent with the immunohistochemical findings, we found that Fos mRNA expression levels were significantly increased in the NAc shell $(156 \%$ increase; $\left.t_{(14)}=2.57, p<0.05\right)$ and OFC $\left(208 \%\right.$ increase; $\left.t_{(20)}=2.31, p<0.05\right)$ of Paired compared with Unpaired mice (Fig. 3B).

In the NAc shell, we delineated Fos + MSNs by their expression of either the Dopamine D1 receptor (Drd1), or Dopamine D2 receptor (Drd2) mRNAs (Fig. $3 E)$. In the OFC, pyramidal neurons and interneurons were distinguished by their expression of their respective vesicular transporter mRNAs, VGLUT1 and VGAT (Fig. 3E). In these brain areas, these neurons play important yet distinct roles in information processing (Dilgen et al., 2013; Smith et al., 2013).

The phenotype distribution of D1R- or D2R-expressing Fos + neurons in the NAc shell was similar between Paired and Unpaired mice (Drd1 $48.7 \%$ vs $48.7 \%$; Drd2 $43.8 \%$ vs $34.5 \%$; Paired vs Unpaired; Fig. $3 C)$. A small proportion of Fos + neurons expressed both Drd1 and Drd2 (3.2\% vs $11.5 \%)$ or could not be identified as Drd1or Drd2-expressing (3.8\% vs 5.3\%; Paired vs Unpaired; data not shown). This suggests that a similar proportion of D1R- and D2Rexpressing neurons were activated after the Pavlovian approach test.

The OFC Fos + ensemble consisted largely of VGLUT1+ neurons (97.5\% vs 94.4\%; Paired vs Unpaired) and a small minority of $V G A T+$ neurons $(2.3 \%$ and 4.9\%; Paired vs Unpaired; Fig. 3D). This suggests that primarily pyramidal neurons were activated in the OFC after Pavlovian approach test.

Experiment 2: Electrophysiological properties of GFP+ and GFP- neurons in the NAc shell and OFC after Pavlovian approach

NAc shell

We measured the firing capacity of NAc shell MSNs after depolarizing current injections across a $0-100 \mathrm{pA}$ range. A three-way ANOVA revealed a significant interaction of Condition $\times$ GFP $\times$ 
Current Injection $\left(F_{(9,486)}=2.76, p<\right.$ $0.01)$ and GFP $\times$ Current Injection $\left(F_{(9,486)}=4.23, p<0.001\right)$ and main effect for $\operatorname{GFP}\left(F_{(1,54)}=4.92, p<0.05\right)$ with no other effects (Fig. $4 A$ ). Therefore, after sucrose memory retrieval, GFP + neurons were more excitable compared with the surrounding GFP - neurons.

We assessed the possible source of this enhanced firing capacity by examining other active and passive membrane properties. No significant interactions for Condition $\times$ GFP were observed for the resting membrane potential, rheobase, or spike kinetics of GFP+ and GFP - neurons in either group (Table 1). However, a two-way ANOVA revealed a significant interaction of Condition $\times \operatorname{GFP}\left(F_{(1,54)}=5.63, p<0.05\right.$; Table 1) for the input resistance. Post hoc analysis indicated a significant increase in the input resistance of GFP + neurons compared with GFP - neurons in Paired $(p<$ $0.001)$ but not Unpaired mice $(p=0.97)$. Furthermore, the increase in the input resistance in the Paired group was associated with a shift in the I/V curve at both positive and negative potentials; Condition $\times$ GFP $\times$ Current Injection $\left(F_{(25,1175)}=4.96, p<0.001\right.$; Fig. 4A).

OFC

In the OFC, spike counts of pyramidal neurons were measured across a 20-300 pA range. A three-way ANOVA did not reveal a significant interaction of Condition $\times$ GFP $\times$ Current Injection $\left(F_{(14,700)}=0.53, p=0.92\right.$; Fig. $\left.4 B\right)$, so Pavlovian conditioning did not modulate the excitability of GFP + neurons. However, there was a significant interaction of Condition $\times$ Current Injection $\left(F_{(14,700)}=2.28, p<0.01\right)$. We then compared only the GFP - neurons in the Paired and Unpaired mice to investigate generalized changes to the majority of neurons, but found no significant difference in spike counts of GFP - neurons between Paired and Unpaired mice in the $\operatorname{OFC}\left(F_{(14,294)}=1.26, p=0.23\right)$.

There was no significant interaction for Condition $\times$ GFP and there were no main effects for Condition or GFP for the resting membrane potential or spike kinetics of GFP + and GFP - neurons in the OFC (Table 1). However, there was a main effect of Condition for the input resistance $\left(F_{(1,51)}=5.69, p<0.05\right)$ and fAHP $\left(F_{(1,51)}=6.09, p<0.05\right)$. Comparison of GFP - neurons from both groups revealed that the input resistance $\left(F_{(1,22)}=\right.$ $4.89, p<0.05)$, but not the fAHP $\left(F_{(1,22)}=3.84, p=0.06\right)$, was larger in Paired compared with Unpaired mice. Furthermore, there was a significant shift in the I/V curve between Paired and Unpaired GFP - neurons $\left(F_{(12,264)}=4.77, p<0.001\right.$; Fig. $\left.4 C\right)$. Therefore, conditioning produced generalized changes to passive membrane properties that were reflective of ion channel opening at rest.
B Final extinction session and spontaneous recovery
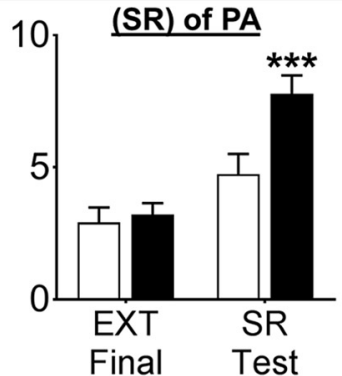

NAc shell Fos+ neuronal phenotype following PA test
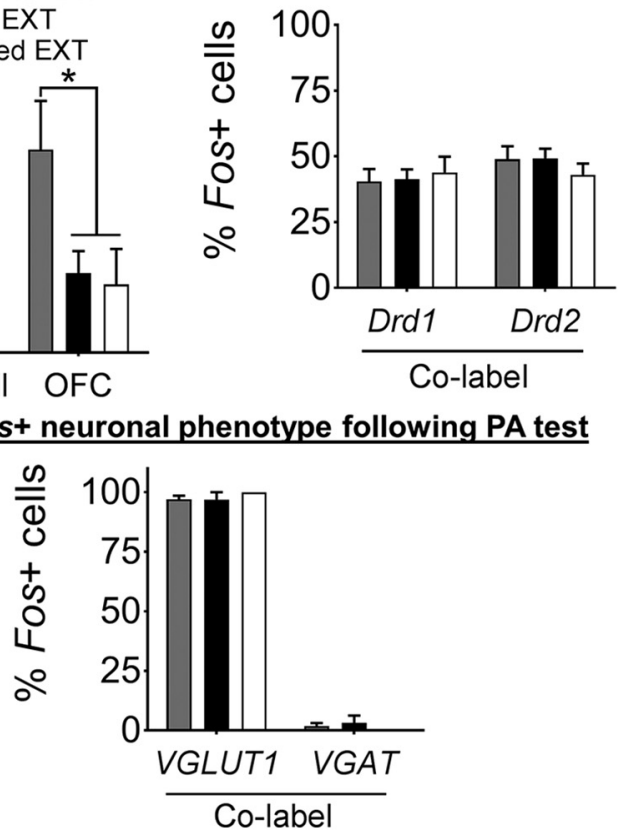

Figure 5. Characterization of activated neurons in the NAc shell and OFC after extinction of Pavlovian approach responding. $A$, Head entries of mice used in in situ hybridization extinction experiments at test $\left(n=8-12 /\right.$ group; $^{* * *} p<0.001$ comparing CS entries and ITI entries). After extinction, head entries made during the $(S$ presentation are reduced in Paired mice. $\boldsymbol{B}$, Extinction of Pavlovian approach 0.001 comparing (S entries and ITI entries). C, Fos expression in the NAc shell and OFC of Paired No EXT, Paired EXT, and Unpaired EXT mice at testing expressed as a percentage of the Paired EXT group. Fos expression is significantly reduced after extinction in both areas $\left({ }^{* *} p<\right.$ Fos + Drd2 neurons was similar between groups. E, Proportion of Fos + neurons in the OFC coexpressing VGLUT1 or VGAT. Fos + neurons were primarily VGLUT1 expressing in all groups. All data are expressed as mean \pm SEM.

Experiment 3: Extinction of Pavlovian approach and NAc shell and OFC Fos expression

We examined the effect of extinction learning on the size and phenotype distribution of NAc shell and OFC ensembles in Paired No EXT, Paired EXT, and Unpaired EXT mice. On test day, a two-way ANOVA revealed a significant interaction of Group $\times$ CS Presentation $\left(F_{(2,29)}=11.38, p<0.001\right.$; Fig. $\left.5 A\right)$. Post hoc analysis revealed no differences between CS and ITI responses in the Paired EXT group $(p=0.61)$ or in the Unpaired EXT group $(p=0.06)$, but Paired No EXT mice made significantly more head entries into the magazine during the CS compared with ITI period $(p<0.001)$.

Extinction is thought to be a process in which the original CS-US association is actively suppressed or "masked" rather than being passively forgotten (Pavlov, 1927; Mackintosh, 1983; Bou- 


\section{A NAc shell: neuronal firing capacity} - GFP+ O GFP-
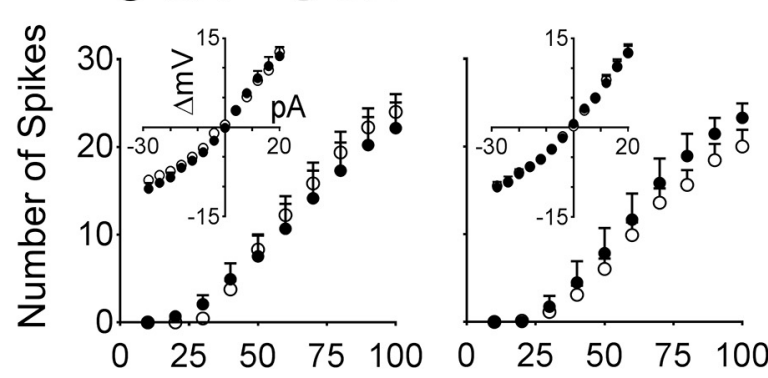

\section{B OFC: neuronal firing capacity}
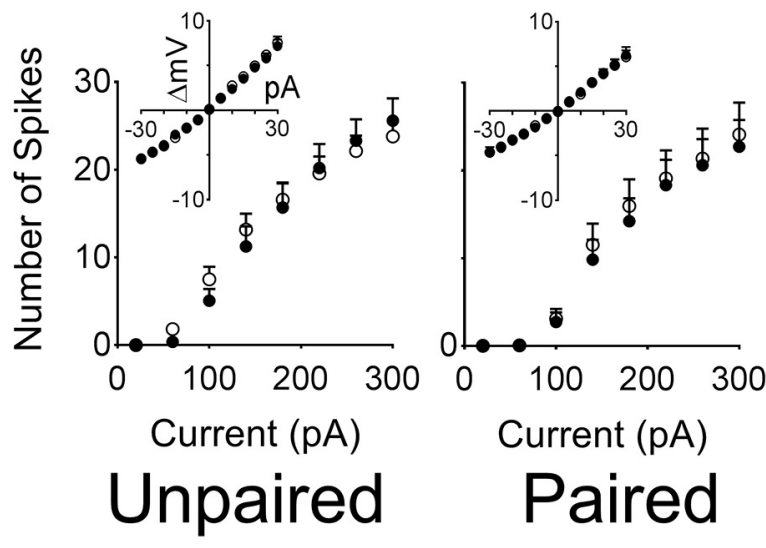

Figure 6. GFP + neurons activated after extinction are of similar excitability to surrounding GFP - neurons in both the NAc shell and OFC. $A$, There was no significant difference between spike counts of GFP + and GFP - neurons in the NAc shell of Paired EXT mice (GFP -,$n=18 / 6 ; \mathrm{GFP}+, n=12 / 6)$. In the Unpaired EXT group, spike counts of GFP + and GFP - neurons were also similar (GFP - $n=13 / 7 ; \mathrm{GFP}+, n=12 / 6)$. Example traces of GFP + and GFP - neurons at $+70 \mathrm{pA}$ from NAc shell Paired EXT mice are shown. Scale bar, $25 \mathrm{mV}, 250 \mathrm{~ms}$. $\boldsymbol{B}$, In the OFC, there was no difference between spike counts of GFP + and GFPneurons in the Paired EXT group (GFP- $n=19 / 7 ; \mathrm{GFP}+, n=18 / 6)$ or the Unpaired EXT group (GFP,$- n=24 / 7 ; \mathrm{GFP}+$, $n=16 / 8$ ). Example traces of GFP + and GFP - neurons at $+140 \mathrm{pA}$ from OFC Paired EXT mice. Scale bar, $25 \mathrm{mV}, 250 \mathrm{~ms}$. Data are expressed as mean \pm SEM; values to the right of GFP - and GFP + denote number of cells recorded/number of mice used.

ton, 2004; Quirk and Mueller, 2008). We investigated whether the Pavlovian approach response could spontaneously recover after extinction, which would suggest that the original CS-US association was suppressed rather than masked. A separate group of wild-type mice underwent acquisition and extinction similar to the Paired EXT mice described above and were then tested for SR 6-7 d after the final extinction session (Fig. 5B). A two-way ANOVA revealed a significant interaction of CS Presentation $X$ Test $\left(F_{(1,44)}=5.30, p<0.05\right)$ and main effects for CS Presentation $\left(F_{(1,44)}=6.48, p<0.05\right)$ and Test $\left(F_{(1,44)}=28.83, p<\right.$ $0.001)$. Post hoc analysis revealed a significant difference between CS and ITI entries at the SR test $(p<0.001)$, but not after the final extinction session $(p=0.73)$. These data suggest that the suppression of Pavlovian approach that we observed here represents an active masking of the CS-US memory.

We next investigated the size of the NAc shell ensemble after extinction by quantifying Fos + neurons in Paired No EXT, Paired EXT, and Unpaired EXT mice. A one-way ANOVA revealed a significant effect of Group on Fos expression in the NAc shell (percentage of Paired No EXT: Paired EXT $=73.2 \%$; Unpaired EXT $=51.2 \% ; F_{(2,21)}=8.68, p<0.01$ ) and OFC (percentage of Paired No EXT: Paired EXT $=39.1 \%$; Unpaired EXT =
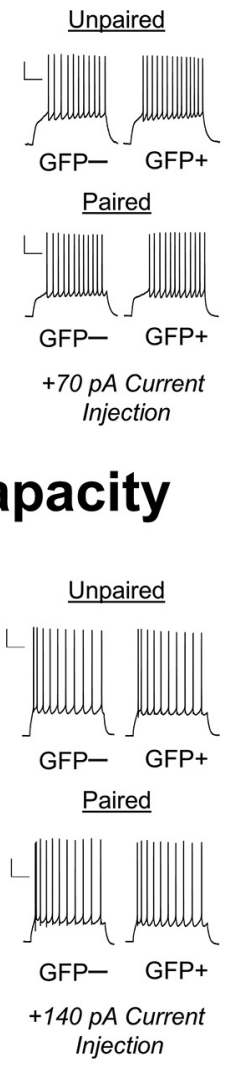

$35.5 \% ; F_{(2,22)}=4.06, p<0.05$; Fig. $\left.5 C\right)$. Post hoc analyses revealed that Fos levels were significantly lower in the Paired EXT group compared with the Paired No EXT group for both brain areas (NAc shell and OFC, $p<0.05)$. Therefore, after extinction, the number of CS-activated neurons was reduced.

Phenotype of Fos-expressing neurons in the NAc shell and OFC after extinction In the NAc shell, the number of Fos + neurons that coexpressed either Drd1 or Drd2 was similar across all groups (Drd1 38.2\% vs $43.9 \%$ vs $42.9 \%$; Drd2 $48.9 \%$ vs $43.06 \%$ vs 49.28\%; Paired No EXT vs Unpaired EXT vs Paired EXT; Fig. 5D). A small proportion of Fos + neurons expressed both $\operatorname{Drd} 1$ and $\operatorname{Drd} 2$ (6.8\% vs $5.3 \%$ vs $3.3 \%)$ or could not be identified as Drd1- or Drd2expressing (6.1\% vs $7.7 \%$ vs $4.1 \%$; Paired No EXT vs Unpaired EXT vs Paired EXT data not shown).

In the OFC, the Fos + neuronal ensemble consisted almost entirely of VGLUT1 neurons (97\% vs $100 \%$ vs $96.9 \%$ ) in all conditions and only an extremely small proportion were VGAT neurons (1.9\% vs $0 \%$ vs $3.1 \%$; Paired No EXT vs Unpaired EXT vs Paired EXT; Fig. 5E).

\section{Experiment 4: Electrophysiological} properties of GFP + and GFP - neurons in the NAc shell and OFC after extinction of Pavlovian approach

We examined the excitability properties of Paired EXT and Unpaired EXT mice in the NAc shell and OFC. After extinction, we found no difference in the firing capacity of either NAc shell or OFC neurons. In the NAc shell, a three-way ANOVA did not reveal a significant interaction of Condition $\times$ GFP $\times$ Current Injection $\left(F_{(9,414)}=0.87, p=0.55\right.$; Fig. $6 A)$ and no significant main effects (Current Injection nor Condition) or further interactions. In the OFC, no main interaction $\left(F_{(14,1008)}=0.45, p=0.96\right.$; Fig. $\left.6 B\right)$ or further effects were observed.

No significant interactions in any other measured electrophysiological parameters were observed (Table 2). However, there was a main effect of GFP for the fAHP $\left(F_{(1,73)}=4.46, p<\right.$ $0.05)$ in the OFC. Overall, after extinction of Pavlovian responding, no increases in the excitability of GFP+ neurons were observed in either the NAc shell or the OFC of Paired EXT mice.

\section{Discussion}

We examined the size, phenotype, and excitability of NAc shell and OFC ensembles after changes in reward-cue association strength; that is, after sucrose conditioning and after extinction learning. We found that exposure to a sucrose-predictive cue activated neurons in both the NAc shell and OFC, whereas cueinduced activation was reduced after extinction learning. In the NAc shell, similar levels of D1R- and D2R-expressing neurons 
Table 2. Basic membrane properties from the NAc shell (MSNs) and OFC (pyramidal neurons) following extinction of Pavlovian approach

\begin{tabular}{|c|c|c|c|c|c|c|c|c|}
\hline & \multicolumn{4}{|l|}{ NAc shell } & \multicolumn{4}{|l|}{$\mathrm{OFC}$} \\
\hline & \multicolumn{2}{|l|}{ Unpaired } & \multicolumn{2}{|l|}{ Paired } & \multicolumn{2}{|l|}{ Unpaired } & \multicolumn{2}{|l|}{ Paired } \\
\hline & GFP- & GFP+ & GFP- & GFP+ & GFP- & GFP+ & GFP- & GFP+ \\
\hline Rheobase (pA) & $41.15 \pm 4.96$ & $38.18 \pm 5.50$ & $45.56 \pm 4.72$ & $45.00 \pm 4.99$ & $88.13 \pm 10.00$ & $107.72 \pm 11.99$ & $121.05 \pm 18.30$ & $119.38 \pm 14.56$ \\
\hline $\operatorname{Ri}(m \Omega)$ & $418.36 \pm 24.83$ & $475.79 \pm 52.81$ & $438.83 \pm 37.22$ & $454.78 \pm 48.13$ & $207.12 \pm 14.67$ & $196.56 \pm 14.38$ & $182.57 \pm 18.97$ & $169.24 \pm 21.71$ \\
\hline AP Peak (mV) & $62.99 \pm 3.81$ & $66.18 \pm 3.12$ & $67.82 \pm 2.85$ & $61.55 \pm 3.26$ & $107.11 \pm 1.72$ & $102.51 \pm 3.40$ & $106.52 \pm 1.71$ & $98.61 \pm 2.81$ \\
\hline $\mathrm{mAHP}(\mathrm{mV})$ & $-8.77 \pm 0.47$ & $-8.99 \pm 0.50$ & $-8.31 \pm 0.45$ & $-7.95 \pm 0.77$ & $-6.86 \pm 1.18$ & $-6.42 \pm 0.83$ & $-7.83 \pm 0.87$ & $-7.84 \pm 1.38$ \\
\hline
\end{tabular}

Data are expressed as mean \pm SEM $\left({ }^{*} p<0.05\right)$. Asterisk indicates main effect of GFP. Liquid junction potential was $-11.1 \mathrm{mV}$ and was not adjusted for. Spike kinetics were calculated as detailed in Table 1 .

$V_{\mathrm{m}}$, Resting membrane potential; $R_{\mathrm{i}}$, input resistance; fAHP, fast AHP; $\mathrm{mAHP}$, medium AHP.

were activated across conditions, whereas in the OFC, the majority of activated neurons were pyramidal cells.

We observed dynamic adaptations in the excitability of neuronal ensembles involved in encoding associative memories, which did not generalize across brain areas. In the NAc shell, but not the OFC, neurons activated after sucrose cue exposure were more excitable than surrounding neurons. Furthermore, after extinction learning, the behaviorally activated ensemble in the NAc shell was no longer more excitable. Our findings provide novel insight into how NAc shell ensembles encode changes in associative strength by recruiting neurons with a different excitability phenotype compared with their surrounding neurons.

\section{Investigating neuronal excitability in the Fos-GFP mouse: methodological considerations}

We have characterized recently behaviorally activated neurons that express GFP (which is highly correlated with Fos expression) from Fos-GFP mice (Koya et al., 2012). It has been shown previously that Fos labels ensembles that are causally involved in the expression of conditioned behaviors (Koya et al., 2009; Fanous et al., 2012; Cruz et al., 2013; Warren et al., 2016). In addition, Fos expression requires sustained calcium signaling and ERK/MAPK phosphorylation (Cruz et al., 2013), but it is not necessarily a direct correlate of spike activity (Luckman et al., 1994). Therefore, similar to other Fos-GFP mice studies (Koya et al., 2012; Whitaker et al., 2016), we suggest that we are mainly recording from neurons with robust, prolonged activation after cue exposure. It should also be noted that certain NAc neurons decrease their firing rate in response to appetitive Pavlovian cues and this decrease is thought to play an important role in appetitive behaviors (Pennartz et al., 1994; Wan and Peoples, 2006; Day et al., 2006). Therefore, intrinsic excitability changes on inhibitory neuronal ensembles may also underlie sucrose and extinction memory recall. However, methods to characterize inhibited neurons electrophysiologically are currently unavailable.

\section{Potential implications and mechanisms for increased excitability of NAc shell ensemble after sucrose memory retrieval}

GFP + neurons in the NAc shell were more excitable than surrounding GFP - neurons after sucrose cue exposure. This excitability change was associated with an increase in the input resistance, which was underpinned by a shift in the I/V curve at both depolarized and hyperpolarized potentials. MSNs express a pronounced inwardly rectifying potassium current, $I_{\mathrm{Kir}}$, as well as voltage-gated currents such as $I_{\mathrm{A}-t y p e}$ currents, which regulate the voltage response at hyperpolarized and depolarized potentials, respectively (Nisenbaum and Wilson, 1995; Perez et al.,
2006; Hibino et al., 2010). At depolarized potentials, shifts in the I/V curve may also be influenced by voltage-gated $\mathrm{Ca}^{2+}$ and $\mathrm{Na}^{+}$ currents (Nisenbaum and Wilson, 1995). Therefore, it is possible that the change in input resistance was primarily due to a modulation of intrinsic $\mathrm{K}^{+}$or $\mathrm{Na}^{+} / \mathrm{Ca}^{2+}$ currents at the dendritic/ somatic level. Interestingly, similar adaptations have been observed in the NAc of obesity-prone rats that consume more food (Oginsky et al., 2016). It is tempting to speculate that the increase in the relative excitability of GFP + neurons represents a potential mechanism to promote "normal" adaptive and "out-of-control" appetitive and consummatory behaviors by increasing the sensitivity to reward-associated cues. Further electrophysiological investigation is necessary to identify the precise intrinsic factors underlying these excitability changes in GFP + neurons after Pavlovian conditioning.

It is possible that the changes that we observed are short-term homeostatic mechanisms that are elicited after acute activation. Homeostatic adaptations in response to high-frequency stimulation or prolonged excitation are, however, typically hyperpolarizing (Turrigiano, 1999; Barth et al., 2004), whereas increased excitability usually occurs after decreased excitatory input (Ishikawa et al., 2009). Furthermore, we did not observe such changes in strongly activated neurons in the OFC and NAc shell after exposure to a cocaine-associated context (J.J. Ziminski, G. Margetts-Smith, E. Koya, unpublished observations). Therefore, we favor the argument that the enhanced excitability that we observed occurred before testing is related to associative memory encoding.

Similar levels of Fos + and Drd1- and Drd2-expressing neurons were observed in the NAc shell after Pavlovian approach. This finding indicates recruitment of ensembles from both direct $(\operatorname{Drd} 1+)$ and indirect $(\operatorname{Drd} 2+)$ pathways that target overlapping, but also distinct structures (Smith et al., 2013), and is consistent with studies that have examined Fos expression during motivated behaviors (Li et al., 2015; Rubio et al., 2015; Caprioli et al., 2017; Soares-Cunha et al., 2016). However, the functional roles of accumbens D1R- and D2R-expressing neurons are complex. Previous studies that used global manipulations of D1R- or D2Rexpressing accumbens neurons indicated opposing (Robinson and Berridge, 2001; Lobo et al., 2010; Chandra et al., 2015) and similar (Soares-Cunha et al., 2016) roles for motivated behaviors mediated by drug and natural rewards, respectively. Such discrepancies may arise from globally manipulating neurons regardless of their behavioral relevance, which may have different effects from neuronal ensemble specific manipulations. For example, neuronal ensemble, but not global, lesioning of the infralimbic cortex altered cue-elicited reward-seeking behavior (Pfarr et al., 2015). To elucidate precisely the functions of D1- and D2R- 
expressing neurons in appetitive behaviors, future studies should use methods that manipulate Fos-expressing neurons from these populations selectively.

\section{Potential implications and mechanisms for the lack of excitability changes in NAc shell ensemble after extinction} After extinction, it is possible that we recorded from a small portion of the original ensemble activated during the initial Pavlovian approach responding. This is consistent with the idea that extinction learning represents a suppression of the original memory (Pavlov, 1927; Mackintosh, 1983; Bouton, 2004; Quirk and Mueller, 2008). Supporting this, we observed SR of responding after extinction. Therefore, it is possible that the excitability of the original NAc shell ensemble activated during appetitive memory recall is reduced after extinction. Extinction learning induces neural adaptations that have been shown to suppress reward seeking (Sutton et al., 2003; Knackstedt et al., 2010), whereas manipulating the excitability of the NAc shell is sufficient to modulate shell-dependent behaviors such as drug-induced locomotor activity (Dong et al., 2006). This suggests that decreasing the excitability in a CS-US coding ensemble in the NAc shell may be sufficient to modify conditioned approach behaviors.

However, recent studies have also suggested that extinction learning may result in the creation of a new neuronal ensemble that mediates the new CS-US contingency (Orsini et al., 2013; Warren et al., 2016). Warren et al. (2016) performed pharmacogenetic lesioning of ventromedial prefrontal cortex Fos-expressing neurons in an operant food self-administration procedure and demonstrated that ablation of Fos-expressing neurons after extinction and food self-administration disinhibited and attenuated nonreinforced food-seeking, respectively. This suggests that, in this area, extinction learning results in the recruitment of a new ensemble distinct from the ensemble activated during initial memory recall. Therefore, in our extinction experiments, GFP+ neurons after extinction may represent a new "extinction" ensemble rather than the same ensemble that encoded the original CS-US association.

\section{Potential reasons for lack of differences in OFC ensemble excitability after sucrose memory retrieval}

Unlike the NAc shell, OFC GFP + neurons did not differ in their excitability compared with GFP - neurons after sucrose memory retrieval despite associated increases in the number of GFP + neurons. This lack of excitability may be due to the fact that these neurons may have undergone transient changes in neuronal excitability during conditioning to confer a permissive learning state (Saar et al., 1998; Mozzachiodi and Byrne, 2010). In support, previous studies have demonstrated that excitability changes in cortical areas may be transient and uncorrelated to the expression of learned behaviors (Moyer et al., 1996). Alternatively, OFC GFP+ neurons may encode a sudden unexpected change in cue-reward associations rather than the retrieval of sucrose memories. However, in vivo electrophysiology studies suggest that the activity of OFC neurons is most robust during presentation of a reward-associated stimulus and reward seeking (Moorman and Aston-Jones, 2014). In addition, pharmacogenetic lesioning of Fos-expressing OFC neurons activated by drug-associated cues attenuate subsequent cueinduced drug seeking (Fanous et al., 2012). Therefore, we favor the explanation that the recruitment of GFP+ neurons in the OFC represents the retrieval of sucrose memory into an ensemble that does not differ in its excitability compared with surrounding neurons rather than recruitment of neurons into an "extinction" ensemble.

\section{Concluding remarks}

By recording selectively from behaviorally activated neurons, here, we illuminate a potentially novel ensemble coding mechanism that reflects changes in appetitive strength associations in the NAc shell. One issue that needs to be resolved here is whether these changes in ensemble excitability in the NAc play a causal role in encoding sucrose and extinction memories. Therefore, future studies may use transgenic tools to manipulate the excitability of these NAc neuronal ensembles directly, for example, by altering $\mathrm{Kv}$ channel expression (Dong et al., 2006) in Fos-expressing neurons using the Fos-tTA mouse (Kandel et al., 2014) and testing their effects on appetitive and extinction memory recall.

\section{References}

Annett LE, McGregor A, Robbins TW (1989) The effects of ibotenic acid lesions of the nucleus accumbens on spatial learning and extinction in the rat. Behav Brain Res 31:231-242. CrossRef Medline

Anschutz DJ, Engels RC, van der Zwaluw CS, Van Strien T (2011) Sex differences in young adults' snack food intake after food commercial exposure. Appetite 56:255-260. CrossRef Medline

Barth AL, Gerkin RC, Dean KL (2004) Alteration of neuronal firing properties after in vivo experience in a FosGFP transgenic mouse. J Neurosci 24:6466-6475. CrossRef Medline

Bouton ME (2004) Context and behavioral processes in extinction. Learn Mem 11:485-494. CrossRef Medline

Burger KS, Berner LA (2014) A functional neuroimaging review of obesity, appetitive hormones and ingestive behavior. Physiol Behav 136:121-127. CrossRef Medline

Caprioli D, Venniro M, Zhang M, Bossert JM, Warren BL, Hope BT, Shaham Y (2017) Role of dorsomedial striatum neuronal ensembles in incubation of methamphetamine craving after voluntary abstinence. J Neurosci 37:1014-1027. Medline

Chandra R, Francis TC, Konkalmatt P, Amgalan A, Gancarz AM, Dietz DM, Lobo MK (2015) Opposing role for Egr3 in nucleus accumbens cell subtypes in cocaine action. J Neurosci 35:7927-7937. CrossRef Medline

Cifani C, Koya E, Navarre BM, Calu DJ, Baumann MH, Marchant NJ, Liu QR, Khuc T, Pickel J, Lupica CR, Shaham Y, Hope BT (2012) Medial prefrontal cortex neuronal activation and synaptic alterations after stressinduced reinstatement of palatable food seeking: a study using c-fos-GFP transgenic female rats. J Neurosci. 32:8480-8490. Medline

Cotel F, Exley R, Cragg SJ, Perrier JF (2013) Serotonin spillover onto the axon initial segment of motoneurons induces central fatigue by inhibiting action potential initiation. Proc Natl Acad Sci U S A 110:4774-4779. CrossRef Medline

Cruz FC, Koya E, Guez-Barber DH, Bossert JM, Lupica CR, Shaham Y, Hope BT (2013) New technologies for examining neuronal ensembles in drug addiction and fear. Nat Rev Neurosci 14:743-754. CrossRef Medline

Daoudal G, Debanne D (2003) Long-term plasticity of intrinsic excitability: learning rules and mechanisms. Learn Mem 10:456-465. CrossRef Medline

Day JJ, Wheeler RA, Roitman MF, Carelli RM (2006) Nucleus accumbens neurons encode Pavlovian approach behaviors: evidence from an autoshaping paradigm. Eur J Neurosci 23:1341-1351. CrossRef Medline

Dilgen J, Tejeda HA, O’Donnell P (2013) Amygdala inputs drive feedforward inhibition in the medial prefrontal cortex. J Neurophysiol 110:221229. CrossRef Medline

Dong Y, Green T, Saal D, Marie H, Neve R, Nestler EJ, Malenka RC (2006) CREB modulates excitability of nucleus accumbens neurons. Nat Neurosci 9:475-477. CrossRef Medline

Fanous S, Goldart EM, Theberge FR, Bossert JM, Shaham Y, Hope BT (2012) Role of orbitofrontal cortex neuronal ensembles in the expression of incubation of heroin craving. J Neurosci 32:11600-11609. CrossRef Medline

Flagel SB, Cameron CM, Pickup KN, Watson SJ, Akil H, Robinson TE (2011) A food predictive cue must be attributed with incentive salience for it to induce c-fos mRNA expression in cortico-striatal-thalamic brain regions. Neuroscience 196:80-96. CrossRef Medline

Gouty-Colomer LA, Hosseini B, Marcelo IM, Schreiber J, Slump DE, Yamaguchi S, Houweling AR, Jaarsma D, Elgersma Y, Kushner SA (2016) Arc expression identifies the lateral amygdala fear memory trace. Mol Psychiatry 21:1153. CrossRef Medline

Hibino H, Inanobe A, Furutani K, Murakami S, Findlay I, Kurachi Y (2010) 
Inwardly rectifying potassium channels: their structure, function, and physiological roles. Physiol Rev 90:291-366. CrossRef Medline

Ishikawa M, Mu P, Moyer JT, Wolf JA, Quock RM, Davies NM, Hu XT, Schlüter OM, Dong Y (2009) Homeostatic synapse-driven membrane plasticity in nucleus accumbens neurons. J Neurosci 29:5820-5831. CrossRef Medline

Kandel ER, Dudai Y, Mayford MR (2014) The molecular and systems biology of memory. Cell 157:163-186. CrossRef Medline

Knackstedt LA, Moussawi K, Lalumiere R, Schwendt M, Klugmann M, Kalivas PW (2010) Extinction training after cocaine self-administration induces glutamatergic plasticity to inhibit cocaine seeking. J Neurosci 30 : 7984-7992. CrossRef Medline

Kourrich S, Calu DJ, Bonci A (2015) Intrinsic plasticity: an emerging player in addiction. Nat Rev Neurosci 16:173-184. CrossRef Medline

Koya E, Golden SA, Harvey BK, Guez-Barber DH, Berkow A, Simmons DE, Bossert JM, Nair SG, Uejima JL, Marin MT, Mitchell TB, Farquhar D, Ghosh SC, Mattson BJ, Hope BT (2009) Targeted disruption of cocaineactivated nucleus accumbens neurons prevents context-specific sensitization. Nat Neurosci 12:1069-1073. CrossRef Medline

Koya E, Cruz FC, Ator R, Golden SA, Hoffman AF, Lupica CR, Hope BT (2012) Silent synapses in selectively activated nucleus accumbens neurons following cocaine-sensitization. Nat Neurosci 15:1556-1562. CrossRef Medline

Li X, Rubio FJ, Zeric T, Bossert JM, Kambhampati S, Cates HM, Kennedy PJ, Liu QR, Cimbro R, Hope BT, Nestler EJ, Shaham Y (2015) Incubation of methamphetamine craving is associated with selective increases in expression of Bdnf and trkb, glutamate receptors, and epigenetic enzymes in cue-activated fos-expressing dorsal striatal neurons. J Neurosci 35:82328244. CrossRef Medline

Lobo MK, Covington HE 3rd, Chaudhury D, Friedman AK, Sun H, DamezWerno D, Dietz DM, Zaman S, Koo JW, Kennedy PJ, Mouzon E, Mogri M, Neve RL, Deisseroth K, Han MH, Nestler EJ (2010) Cell type-specific loss of BDNF signaling mimics optogenetic control of cocaine reward. Science 330:385-390. CrossRef Medline

Luckman SM, Dyball RE, Leng G (1994) Induction of c-fos expression in hypothalamic magnocellular neurons requires synaptic activation and not simply increased spike activity. J Neurosci 14:4825-4830. Medline

Mackintosh NJ (1983) Conditioning and associative learning. Oxford: Clarendon.

Moorman DE, Aston-Jones G (2014) Orbitofrontal cortical neurons encode expectation-driven initiation of reward-seeking. J Neurosci 34:1023410246. CrossRef Medline

Moyer JR Jr, Thompson LT, Disterhoft JF (1996) Trace eyeblink conditioning increases $\mathrm{CA} 1$ excitability in a transient and learning-specific manner. J Neurosci 16:5536-5546. Medline

Mozzachiodi R, Byrne JH (2010) More than synaptic plasticity: role of nonsynaptic plasticity in learning and memory. Trends Neurosci 33:17-26. CrossRef Medline

Nisenbaum ES, Wilson CJ (1995) Potassium currents responsible for inward and outward rectification in rat neostriatal spiny projection neurons. J Neurosci 15:4449-4463. Medline

Oginsky MF, Maust JD, Corthell JT, Ferrario CR (2016) Enhanced cocaineinduced locomotor sensitization and intrinsic excitability of NAc medium spiny neurons in adult but not in adolescent rats susceptible to diet-induced obesity. Psychopharmacology (Berl) 233:773-784. CrossRef Medline

Orsini CA, Yan C, Maren S (2013) Ensemble coding of context-dependent fear memory in the amygdala. Front Behav Neurosci 7:199. CrossRef Medline

Pavlov IP (1927) Conditioned reflexes: an investigation of the physiological activity of the cerebral cortex.

Paxinos G, Franklin K (2001) The mouse brain in stereotaxic coordinates. San Diego: Academic.

Pennartz CM, Groenewegen HJ, Lopes da Silva FH (1994) The nucleus accumbens as a complex of functionally distinct neuronal ensembles: an integration of behavioural, electrophysiological and anatomical data. Prog Neurobiol 42:719-761. CrossRef Medline

Perez MF, White FJ, Hu XT (2006) Dopamine D(Anczak and Nogler) receptor modulation of $\mathrm{K}(+)$ channel activity regulates excitability of nucleus accumbens neurons at different membrane potentials. J Neurophysiol 96:2217-2228. CrossRef Medline
Petrovich GD (2011) Learning and the motivation to eat: forebrain circuitry. Physiol Behav 104:582-589. CrossRef Medline

Petrovich GD, Gallagher M (2007) Control of food consumption by learned cues: a forebrain-hypothalamic network. Physiol Behav 91:397-403. CrossRef Medline

Pfarr S, Meinhardt MW, Klee ML, Hansson AC, Vengeliene V, Schönig K, Bartsch D, Hope BT, Spanagel R, Sommer WH (2015) Losing control: excessive alcohol seeking after selective inactivation of cue-responsive neurons in the infralimbic cortex. J Neurosci 35:10750-10761. CrossRef Medline

Quirk GJ, Mueller D (2008) Neural mechanisms of extinction learning and retrieval. Neuropsychopharmacology 33:56-72. CrossRef Medline

Robinson TE, Berridge KC (2001) Incentive-sensitization and addiction. Addiction 96:103-114. CrossRef Medline

Rubio FJ, Liu QR, Li X, Cruz FC, Leão RM, Warren BL, Kambhampati S, Babin KR, McPherson KB, Cimbro R, Bossert JM, Shaham Y, Hope BT (2015) Context-induced reinstatement of methamphetamine seeking is associated with unique molecular alterations in Fos-expressing dorsolateral striatum neurons. J Neurosci 35:5625-5639. CrossRef Medline

Saar D, Grossman Y, Barkai E (1998) Reduced after-hyperpolarization in rat piriform cortex pyramidal neurons is associated with increased learning capability during operant conditioning. Eur J Neurosci 10:1518-1523. CrossRef Medline

Santini E, Quirk GJ, Porter JT (2008) Fear conditioning and extinction differentially modify the intrinsic excitability of infralimbic neurons. J Neurosci 28:4028-4036. CrossRef Medline

Schoenbaum G, Setlow B, Saddoris MP, Gallagher M (2003) Encoding predicted outcome and acquired value in orbitofrontal cortex during cue sampling depends upon input from basolateral amygdala. Neuron 39: 855-867. CrossRef Medline

Schoenbaum G, Saddoris MP, Stalnaker TA (2007) Reconciling the roles of orbitofrontal cortex in reversal learning and the encoding of outcome expectancies. Ann N Y Acad Sci 1121:320-335. CrossRef Medline

Sehgal M, Ehlers VL, Moyer JR Jr (2014) Learning enhances intrinsic excitability in a subset of lateral amygdala neurons. Learn Mem 21:161-170. CrossRef Medline

Singh T, McDannald MA, Haney RZ, Cerri DH, Schoenbaum G (2010) Nucleus accumbens core and shell are necessary for reinforcer devaluation effects on Pavlovian conditioned responding. Front Integr Neurosci 4:126. CrossRef Medline

Smith RJ, Lobo MK, Spencer S, Kalivas PW (2013) Cocaine-induced adaptations in D1 and D2 accumbens projection neurons (a dichotomy not necessarily synonymous with direct and indirect pathways). Curr Opin Neurobiol 23:546-552. CrossRef Medline

Soares-Cunha C, Coimbra B, David-Pereira A, Borges S, Pinto L, Costa P, Sousa N, Rodrigues AJ (2016) Activation of D2 dopamine receptorexpressing neurons in the nucleus accumbens increases motivation. Nat Commun 7:11829. CrossRef Medline

Sutton MA, Schmidt EF, Choi KH, Schad CA, Whisler K, Simmons D, Karanian DA, Monteggia LM, Neve RL, Self DW (2003) Extinction-induced upregulation in AMPA receptors reduces cocaine-seeking behaviour. Nature 421:70-75. CrossRef Medline

Turrigiano GG (1999) Homeostatic plasticity in neuronal networks: the more things change, the more they stay the same. Trends Neurosci 22 : 221-227. CrossRef Medline

van Strien T, Peter Herman C, Anschutz D (2012) The predictive validity of the DEBQ-external eating scale for eating in response to food commercials while watching television. Int J Eat Disord 45:257-262. CrossRef Medline

Wan X, Peoples LL (2006) Firing patterns of accumbal neurons during a Pavlovian-conditioned approach task. J Neurophysiol 96:652-660. CrossRef Medline

Warren BL, Mendoza MP, Cruz FC, Leao RM, Caprioli D, Rubio FJ, Whitaker LR, McPherson KB, Bossert JM, Shaham Y, Hope BT (2016) Distinct Fos-expressing neuronal ensembles in the ventromedial prefrontal cortex mediate food reward and extinction memories. J Neurosci 36:6691-6703. CrossRef Medline

Whitaker LR, Carneiro de Oliveira PE, McPherson KB, Fallon RV, Planeta CS, Bonci A, Hope BT (2016) Associative learning drives the formation of silent synapses in neuronal ensembles of the nucleus accumbens. Biol Psychiatry 80:246-256. CrossRef Medline 